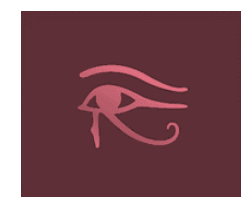

\title{
OS SENTIDOS DO RETORNO AO PROCESSO DE ESCOLARIZAÇÃO PARA JOVENS E ADULTOS ASSENTADOS DA REFORMA AGRÁRIA DA REGIÃO DE PROMISSÃO/SÃO PAULO
}

\author{
Raíza Cruz de Souza \\ raiza3z@hotmail.com
}

\author{
Márcia Aparecida Vieira \\ mavieira@unimep.br
}

Universidade Metodista de Piracicaba

\begin{abstract}
RESUMO: Visando compreender a Educação de Jovens e Adultos do Assentamento Reunidas, vinculado ao Movimento dos Trabalhadores Rurais Sem Terra - MST, em Promissão/São Paulo, buscou-se reconhecer e registrar a percepção desses alunos sobre o processo de escolarização que vivenciam tardiamente. Mediante entrevistas, foram acessadas as expectativas dos alunos assentados e o papel da educação na vida destes, a partir da promoção de um debate sobre educação e o acesso aos direitos. Percebeu-se que a escola é, para eles, sinônimo de luta e de conquista; portanto, valorizam e reconhecem a importância dos saberes adquiridos em sala de aula, pois, além disso, esse ambiente tornou-se um espaço privilegiado para abordar questões cotidianas que se mostram desafiadoras no âmbito individual, mas, ao serem compartilhadas e percebidas como coletivas, encontra-se possibilidades de busca conjunta por superação.
\end{abstract}

PALAVRAS-CHAVE: Educação de Jovens e Adultos, Escolarização, Sentidos.

\section{THE MEANING OF THE REGRESS TO THE SCHOOLING PROCESS FOR (YOUNG PEOPLE AND) ADULT SETTLERS FROM THE LAND REFORM IN THE PROMISSÃO/SÃO PAULO REGION.}

\begin{abstract}
Aiming to understand the Education of Young People and Adults from the settlement "Reunidas", bound to the Landless Movement, in Promissão/São Paulo, it sought to recognize and to register the perception of students about late schooling process. Through interviews, the settler students' expectations were accessed and the role of education in their lives from the promotion of debate about education and access to rights. We realized that the school is a synonymous of fight and conquest for them; therefore, they value and recognize the importance of socialized content in the classroom, furthermore, this environment became a privileged space to approach daily life questions that show themselves challenging in the individual ambit, but when shared and noticed as collective it is found the possibilities of joint search by overcoming.

KEYWORDS: Education of Young People and Adults, Schooling, Meaning.
\end{abstract}

Olh@res, Guarulhos, v. 4, n. 1, p. 182-203, maio 2016. 


\section{Introdução}

Primeiramente nos cabe expor que o Assentamento Reunidas é um dos maiores do Estado de São Paulo, com cerca de 600 famílias, tendo uma área de 17.138 hectares (IOKOI; ANDRADE; REZENDE; RIBEIRO, 2005, p.176). Em 1985, depois de quase uma década de conflitos entre o ex-proprietário das terras e os sitiantes dos arredores, deu-se início às primeiras iniciativas de luta pela terra, organizada em acampamentos até 1987, um ano após a desapropriação pelo Governo Federal. A primeira ocupação foi realizada por 44 famílias vinculadas ao Movimento dos Trabalhadores Rurais Sem Terra - MST vindas dos municípios de Sumaré e Campinas e, assim, foram seguidas por outras 607 cadastradas em sindicatos da região de Promissão/SP. Desta maneira, em 1988 foram delimitadas as 10 agrovilas (D’AQUINO, 1997, p.47), de forma que, concomitantemente, fundou-se o assentamento com a delimitação dos lotes no ano seguinte pelo Instituto Nacional de Colonização e Reforma Agrária - Incra. Dentre essas existe a Agrovila de Birigui, que ganhou esse nome devido à maioria de famílias serem oriundas do município de mesmo nome, região do assentamento na qual se encontram os alunos com os quais realizamos a pesquisa.

A compreensão do vínculo deste assentamento ao MST é importante para a entendermos este trabalho, pois esse movimento social prioriza, além da luta pela terra, o acesso a uma educação de qualidade, que reconheça nos saberes dos camponeses o ponto de partida para o processo educativo, ao assumir a tarefa de formar "seres humanos com dignidade, identidade e projeto de futuro" (CALDART, 2003, p.51). Assim, a denominação "Sem Terra" não ocorre porque se identificam com a falta e sim com a afirmação da luta por justiça social e, a partir deste posicionamento, se assumem como sujeitos que exigem o "seu lugar no mundo, na história" (p.53). A Pedagogia do Movimento, segundo Caldart (2003), está para além da sala de aula, porque apreende o mundo a partir da realidade e em função dessa, buscando transcendê-la sem, no entanto, perder suas referências de origem, sua raiz.

Desta forma, na busca por compreender e documentar a percepção dos alunos sobre a Educação de Jovens e Adultos nos assentamentos rurais, neste caso, alunos da Agrovila Birigui do Assentamento Reunidas, foi necessário reconhecer o universo do aluno jovem e adulto, a Educação de Jovens e Adultos e a Educação do Campo, por meio de uma revisão bibliográfica que precedeu as entrevistas. 
Os sentidos do retorno ao processo de escolarização para jovens e adultos assentados da reforma agrária da região de Promissão/São Paulo

Partimos do acesso ao documento das Diretrizes Curriculares Nacionais para a EJA (BRASIL, CNE, 2000). Esse nos informa que, desde a Lei 9.394/96 (BRASIL, 1996), a EJA integra a educação básica, tanto no ensino fundamental quanto no ensino médio, mas, como afirma o parecer das diretrizes da EJA, ainda faltavam diretrizes próprias devido às especificidades da modalidade, bem como o reconhecimento formal da dívida social com uma enorme população de nosso país, que não teve garantido o acesso à escola em idade própria.

O documento apresenta, historicamente, as mazelas da EJA no Brasil, o perfil dos alunos, a necessidade de formação docente específica, as bases legais reconhecidas e as funções reparadora, equalizadora, qualificadora ou permanente. A função reparadora significa o reconhecimento e a restauração de um direito historicamente negado. Tal reconhecimento está relacionado à reparação de uma dívida social que deve ser declarada e assumida. A função equalizadora assume o desafio de buscar equidade, que neste caso visa garantir mais oportunidades para aqueles que não tiveram, oferecendo ou restabelecendo o direito à educação escolar. A função permanente também pode ser reconhecida como qualificadora: "Mais do que uma função, ela é o próprio sentido da EJA" (CNE, 2000, p. 10), pois está fundamentada na busca constante do ser humano por conhecimento, atualização e realização plena. A função permanente vem reafirmar que, para descobrir novos conhecimentos, atualizar-se e se realizar não há idade definida. Por essa razão, a educação de qualidade para jovens e adultos deve acontecer ao longo da vida.

As funções acima referidas, apesar de distintas, complementam-se, pois no próprio texto das Diretrizes, há a afirmação de que, uma vez consolidadas as funções reparadora e a equalizadora será possível buscar o sentido da Educação de Jovens e Adultos na função permanente, qualificadora. (BRASIL, CNE, 2000, p. 11).

Além disso, o documento das Diretrizes Curriculares Nacionais - DCN traz um apelo dos setores envolvidos com a Educação de Jovens e Adultos, pelo reconhecimento da especificidade do trabalho a ser desenvolvido, não apenas como uma modalidade da Educação Básica, mas, sobretudo, como um direito a ser garantido a todos os jovens e adultos do país.

Ainda de acordo com tal documento, os alunos da EJA pertencem ao segmento mais empobrecido da população. Entre os alunos, especialmente os que estão na faixa etária acima de 30 anos, prevalecem a origem rural e a vivência das dificuldades de frequentar as poucas escolas no campo.

Olh@res, Guarulhos, v. 4, n. 1, p. 182-203, maio 2016. 
Com isso, quando buscamos explorar o entendimento sobre o que seria propriamente um indivíduo analfabeto acessamos parte do material elaborado por Magda Soares (2001). A autora discute o que podemos compreender sobre o que é alfabetização e a proposta do letramento.

No entanto temos dificuldade em definir exatamente quem pode ser considerado analfabeto. O próprio termo expressa uma ausência. Se entendermos que a necessidade da habilidade de escrever e ler, na vida de um ser humano, envolve o fato de utilizar os bens sociais, culturais e econômicos relacionados a esses dois pontos, apenas alfabetizar não é o suficiente, segundo Soares (2001). Dessa forma, a autora nos apresenta o que seria o letramento, termo que tem sua origem na língua inglesa - literacy, que significa promover a condição de letrado, isto é, um sujeito utilizando da escrita e da leitura de maneira competente. São indivíduos que não apenas tomaram conhecimento sobre o alfabeto, mas que também aprenderam as práticas sociais da leitura e da escrita.

Trata-se da apropriação daquilo que essas habilidades oferecem como acessar um texto e ter pensamento crítico sobre ele ou até mesmo agregar o aprendido em uma obra ao seu cotidiano - pegar um ônibus, ler uma notícia no jornal, entender a embalagem de um alimento, escrever uma carta etc.. Aprender a ler e escrever é, portanto, muito mais abrangente do que o parâmetro utilizado pelo Instituto Brasileiro de Geografia e Estatística - IBGE para a realização do Censo, do qual considera um sujeito alfabetizado aquele com cinco anos ou mais de idade que seja "capaz de ler e escrever pelo menos um bilhete simples no idioma que conhecesse" (BRASIL, MEC/Inep, 2003, p.06). Envolverse com as práticas sociais da escrita e leitura adquire uma condição e um estado a esse sujeito que o redefine em seus espaços de participação na sociedade, isto é, não é apenas conhecer e discriminar as letras do alfabeto.

Segundo as diretrizes da EJA (BRASIL, CNE, 2000), a maioria dos analfabetos do nosso país está em idade adulta, vive em regiões com baixo Índice de Desenvolvimento Humano - IDH, mora no interior das cidades, principalmente no campo e são afrodescendentes. Dessa maneira, a EJA tem como propósito suprir a dívida social que se tem com essas pessoas que não tiveram acesso aos bens sociais seus por direito.

Acessar esse direito é fundamental a todo ser humano. Isso porque ter a leitura e a escrita como instrumentos permite que um sujeito agregue opções de se expressar e participar efetivamente de seu meio social. Negar esse direito é como negar uma sequência de outros direitos. Tais indivíduos não poderão participar, de forma integral, de seu papel como cidadãos, quando qualquer um dos seus direitos lhes for negado. 
Os sentidos do retorno ao processo de escolarização para jovens e adultos assentados da reforma agrária da região de Promissão/São Paulo

Com isso pudemos notar que não se trata apenas de atividades de escrita e leitura, mas de verdadeira promoção de uma educação democrática, que possibilite acesso a importantes elementos imprescindíveis para o exercício da cidadania. Essa concepção de processo educativo possibilita a compreensão do quanto o analfabetismo está atrelado à desigualdade social, como nos é apresentado no Mapa do Analfabetismo no Brasil (BRASIL, INEP, 2003), estudo realizado pelo Instituto Nacional de Estudos e Pesquisas Educacionais Anísio Teixeira - Inep. Segundo dados desta pesquisa, a taxa de analfabetismo era de 1,4\% nas famílias que possuíam rendimento superior a dez salários mínimos, número bem distante, quando se analisou os domicílios que tinham renda menor que um salário mínimo que eram de $29 \%$.

Distribuição de renda e de educação são duas ações que caminham juntas. Políticas estruturais de distribuição de renda (como a reforma agrária) assim como as emergenciais (como os programas de renda mínima) aumentam as chances de permanência das crianças e jovens nas escolas. (BRASIL, MEC/Inep, 2003, p.11)

\subsection{Breve Histórico e Perfil dos Alunos da EJA}

Ao acessar as bases históricas da EJA apresentadas no documento das Diretrizes dessa modalidade (BRASIL, CNE, 2000), reconhecemos que as primeiras iniciativas sistemáticas que tinham relação com a educação de jovens e adultos apareceram nos anos de 1930. Com o fim da ditadura do Estado Novo não convinha ter tantos analfabetos, principalmente com o número crescente de egressos do campo para o meio urbano, impulsionados pelo crescimento das indústrias, que exigiam níveis básicos de instrução de seus funcionários.

Em 1947 ocorreu a Campanha de Educação de Adolescentes e Adultos, que previa a alfabetização em três meses e o ensino primário em dois blocos de sete meses. Tratavase de uma iniciativa voltada principalmente para o meio rural. Desta iniciativa, derivouse a Campanha Nacional de Educação Rural (1952). Mesmo buscando efetivar um bem a esta população, essas campanhas tinham a visão de que os analfabetos eram serem incapazes e marginais, o que lhes garantia um tratamento infantilizado.

Essa concepção é questionada por Paulo Freire, que se tornou, no final dos anos de 1950 e início dos anos de 1960, uma das maiores referências para a EJA. "A sua proposta de alfabetização, teoricamente sustentada em uma outra visão socialmente compromissada, inspirará os programas de alfabetização e de educação popular realizados no país nesse início dos anos 60.” (BRASIL, CNE, 2000, p.49-50). 
Em novembro de 1963 cria-se o Plano Nacional de Alfabetização, que disseminaria programas por todo o país segundo o "Sistema Paulo Freire", mas o plano foi interrompido, devido ao golpe de 1964. A repressão calou movimentos sociais e demais grupos que buscavam efetivar a educação popular. Mas ter uma população com grande número de analfabetos não era bem visto, nem mesmo pelo regime militar, que buscou promover ações mais conservadoras, com a Cruzada ABC (1965) e o Movimento Brasileiro de Alfabetização - Mobral (1967).

Os programas e campanhas até os dias atuais foram aos poucos atingindo a compreensão de que as políticas públicas voltadas para a EJA não podem ser concebidas como caridade. As propostas atuais da EJA, especialmente as inspiradas pela Educação do Campo, com ampla participação dos movimentos sociais, estão comumente ancoradas numa concepção libertadora de educação, que abordaremos melhor na sequência deste texto.

A partir do exposto seguimos buscando reconhecer o perfil dos alunos da EJA. Assim, para adentrarmos nesse universo tão diversificado recorremos à leitura de cadernos da coleção disponibilizada pelo Mistério da Educação: "Trabalhando com a Educação de Jovens e Adultos (2006) ". O Caderno 1, sob o título “Alunas e Alunos da EJA", frisa que, para se conhecer esses sujeitos é importante descobrir os motivos que os levam a procurar a EJA, aquilo que desejam saber unido ao que já sabem e ainda não sabem e suas relações com o ambiente do trabalho e a sociedade da qual estão inseridos.

Esses educandos levam para a escola uma considerável bagagem de experiências, tendo muitos conhecimentos, crenças e valores já construídos. Com isso, muitas vezes são os representantes de suas famílias e estão inclusos na dinâmica do mundo do trabalho, tendo valores éticos e morais formados segundo diversas vivências.

A concepção de mundo desses alunos é elaborada a partir de diversas influências de seus ambientes culturais, sociais, familiares e profissionais. $O$ professor que recepciona esses alunos precisa valorizar tais conhecimentos, tendo-os como ponto de partida do processo de aprendizagem dos educandos.

Referente ao conhecimento já adquirido por esses alunos, o Caderno 1 apresenta uma divisão: o saber sensível e o saber cotidiano. O Saber Sensível é apresentado no caderno como aquele que vem antes da reflexão. Exposto como o saber do corpo, as impressões vindas dos primeiros contatos do sujeito com o mundo, que é a união da "percepção das coisas e do outro" (BARRETO, 2006a, p.06), que infelizmente pouco se valoriza, na maioria das salas de aulas. 
Os sentidos do retorno ao processo de escolarização para jovens e adultos assentados da reforma agrária da região de Promissão/São Paulo

De acordo com Barreto (2006a), a partir do conhecimento sensível é possível acessar o conhecimento formal. Utilizar estes saberes da experiência dos alunos permite que os conteúdos sistematizados sejam aprendidos de forma mais prazerosa e rica.

O Saber Cotidiano, refere-se ao saber reflexivo. Por sua vez, vem do saber amadurecido, isto é, vem da experiência já tida em relação a algo ou alguém. Esse conhecimento foi adquirido segundo valores éticos e morais, construídos antes da vivência escolar. Trata-se de um saber também pouco valorizado, mas muito utilizado pelo aluno da EJA. Ao contrário do que se pensa, esse saber não é preso a atender necessidades imediatas; por estar aliado à reflexão, permite que o sujeito se afaste do objeto ao analisá-lo e, com isso, possa recriar sobre aquilo que observa.

Conforme apresentado no Caderno 1 da EJA existe uma particularidade em relação ao motivo da busca pelo ensino escolar: seus alunos têm necessidades particulares, precisam estar inseridos em um mundo letrado de forma completa, uma posição que é sua por direito. Eles desejam ser sujeitos ativos, capazes de crescer cultural, social e economicamente. A escola tem, então, como desafio criar um ambiente onde alunos e professores sejam sujeitos ativos no processo de escolarização, para que os conhecimentos adquiridos somem efetivamente na vida dos envolvidos.

Em relação à sala de aula da EJA, é comum estas salas terem como marca a diversidade cultural, de modo que a cultura popular seja refletida nas aulas, exigindo que o aprendizado se dê de forma dinâmica e coletiva. Ao investigar a cultura dos alunos da EJA há um ponto em comum: a marca da exclusão. Já sobre a sua condição socioeconômica, em sua maioria, são pessoas que têm pouco poder aquisitivo e por isso seu consumo gira mais em torno do que é básico para a sua sobrevivência. A educação de jovens e adultos não é apenas uma questão pedagógica e sim social e política, como afirmava Paulo Freire há tanto tempo.

Outro ponto forte é a autoimagem negativa da maioria desses alunos, por suas experiências marcadas pela exclusão, das quais estudar para eles se remete a aquilo que não deu certo, afetando drasticamente sua autoestima. O professor tem um papel determinante na reconfiguração da imagem da escola e do ato de aprender, para esses alunos. Assim, ir à escola terá que se associar com a produção de conhecimento e não apenas a um processo de assimilação de conteúdos. 
O reconhecimento da existência de uma sabedoria no sujeito, proveniente de sua experiência de vida, de sua bagagem cultural, de suas habilidades profissionais, certamente, contribui para que ele resgate uma autoimagem positiva, ampliando sua autoestima e fortalecendo sua autoconfiança. (BARRETO, 2006, p.19)

O que é também muito comum nos alunos da EJA é a marca do trabalho. Com isso, sejam jovens ou adultos vão, em sua maioria, para a sala de aula depois de um longo dia de trabalho. No ambiente rural, a dinâmica das aulas da EJA ainda tem como influência períodos de colheita, de chuva e seca, além de questões de horários e regiões, tendo ainda como agravante as longas distâncias entre as moradias dos alunos e a sala de aula. Como colocado por Barreto (2006a), o trabalho é muitas vezes tanto o motivo de ter deixado os estudos como o impulsionador para voltar a estudar. A escola acaba sendo procurada pela questão do emprego, já que o estudo é um dos requisitos para muitas vagas profissionais.

No caderno 1 da EJA (BARRETO, 2006a) afirma-se também que existem outros motivos que levam essas pessoas a retomar seus estudos além da busca por emprego, o que deu ainda mais impulso ao nosso projeto de pesquisa. "Vale destacar, que outras motivações levam os alunos jovens e adultos para a escola. Uma delas é a satisfação pessoal, a conquista de um direito, a sensação de capacidade e dignidade que traz satisfação pessoal”. (BARRETO, 2006a, p.22)

Mais do que uma formação profissionalizante, a escola precisa sempre efetivar uma das suas naturezas, que é ser um espaço de inserção social. Para Freire (2001), a Educação Popular tem como papel promover no aluno a capacidade de se "mobilizar em direção de objetivos próprios” (p.14). Com isso não acabe apenas ensinar conteúdos, mas também permitir a construção de uma visão de mundo, que se dá por um processo dinâmico, com análises de conteúdos escolares e da realidade concreta do aluno. Sua proposta era uma pedagogia libertadora que fazia da educação um ato político, que contribui para a formação de sujeitos capazes de atuar politicamente, buscando transformar a sociedade em que vivem.

\subsection{Por uma Educação Libertadora}

Ainda na busca por compreender o universo dos alunos da EJA o Caderno 5 (2006b), intitulado “O Processo de Aprendizagem dos Alunos e Professores” discute sobre as concepções que existem sobre o conhecimento e, como isso, se relaciona com a forma com que esses jovens e adultos aprendem. Com ênfase na concepção democrática 
Os sentidos do retorno ao processo de escolarização para jovens e adultos assentados da reforma agrária da região de Promissão/São Paulo

do conhecimento, o caderno reforça aquilo que Freire compreendia como o caminho que se constrói o conhecer. O homem seria, segundo Paulo Freire, um ser de relação, que não se constitui sozinho, e que, portanto, necessita do outro para se desenvolver e que, ao mesmo tempo, o mundo precisa dele para estender a sua existência.

De acordo com Freire (1999), um conhecimento construído democraticamente também nasce das relações, nas quais o saber se constrói no momento em que esse é vivenciado e compartilhado pelos indivíduos envolvidos e não com a memorização de conceitos, como se acredita uma concepção do saber mais tradicional. Estarem incluídos em um ambiente não é um processo de simples adaptação, ao contrário dos outros animais, somos uma espécie que se utiliza da natureza para criar e para preencher aquilo que nos falta. "Onde há vida, há inacabamento. Mas só entre os homens e as mulheres o inacabamento se tornou consciente" (FREIRE, 1999, p. 36). Sendo um ser de relação e que reconhece suas faltas, o homem, segundo Freire, tem a capacidade de entender o infinito a partir da sua finidade, de forma que busca transcender sua existência. E é na construção de saberes que o homem encontrou uma das suas formas mais ricas de encontrar a sua transcendência.

Como fazemos isso? Somos criaturas que tridimensionamos o tempo, isto é, podemos aprender com as experiências de pessoas anteriores a nós; podemos agir no hoje e a união dessas experiências nos fornece conhecimento para planejar o amanhã. Ter a dimensão do passado, presente e futuro permite que o homem note a consequência de suas ações em diferentes momentos da história, o que nos possibilita sermos sujeitos históricos, como nos coloca Freire. "Faz hoje o que se tornou possível pelo ontem. Fará amanhã o que está semeando hoje" (BARRETO apud FREIRE, 2006b, p. 55).

Desta forma, se o saber se dá por meio da relação entre as pessoas, os espaços e os tempos, a sala de aula que busca por uma educação libertadora deve incentivar a coletividade entre os seus alunos. A grande maioria dos alunos da EJA construiu seus conhecimentos por meios coletivos antes de frequentar uma escola, onde viveram aquilo que aprenderam, absorvendo o saber pela experiência e não apenas pela escuta de um discurso. Se enxergarmos a educação com um ato é possível concluir que este não é transferível, como afirmado no caderno, cada indivíduo precisa ter sua experiência, vivenciar situações, para possuir determinado conhecimento. Isso reforça a afirmação de Paulo Freire: "Ninguém educa ninguém, ninguém educa a si mesmo, os homens se educam entre si, mediatizados pelo mundo" (FREIRE, 1987, p. 79). 
Com isso temos duas considerações de Vera Barreto, em "Paulo Freire para Educadores" (1998): primeiro, se o conhecimento nasce do agir e do viver, então todos nós construímos saberes, dos quais não há maior nem menor e sim formas diferentes de conhecer, e segundo, as propostas de conteúdos a se ensinar de um educador devem se relacionar com a dinâmica da qual se aprende aquilo que se vive.

Quando se busca afirmar um conhecimento construído coletivamente e pelas experiências acabamos por encontrar a educação libertadora como uma opção. Seus elementos fundamentais, como colocado por Barreto (1998) segundo preceitos de Freire são: o cultivo constante do diálogo entre educador e educandos; a escolha política progressista, por parte do educador; o compromisso com o conhecimento, no qual conteúdos científicos conversem com a realidade concreta do aluno; a aproximação do professor daquilo que pretende ensinar, o que o faz aprender constantemente; e o ato de cultivar o prazer em estudar.

\subsection{A EJA e a Educação do Campo}

As propostas para a Educação de Jovens e Adultos articulam-se com a Educação do Campo, o que entra em nosso contexto, devido ao fato de nosso campo de pesquisa ser o Assentamento Reunidas localizado no município Promissão/SP, como anteriormente colocado.

Segundo Parecer 36/2001 das Diretrizes Operacionais para a Educação Básica nas Escolas do Campo (BRASIL, CNE, 2001) o campo é mais do que um território não urbano, trata-se de um ambiente que proporciona a interação do homem com a natureza, que resulta a produção de condições de existência social e realizações da sociedade humana. Trata-se de um “(...) espaço heterogêneo, destacando a diversidade econômica, (...), a presença de fecundos movimentos sociais, a multiculturalidade, as demandas por educação básica (...) com os meios de comunicação e a cultura letrada”. (BRASIL, CNE, 2001, p.02)

É importante compreendermos que Rural e Urbano equivalem-se, no sentido de que ambos são espaços que permitem o homem buscar sua existência na sociedade. "E, neste particular, o campo hoje não é sinônimo de agricultura ou de pecuária. (...) Assim sendo, a inteligência sobre o campo é também a inteligência sobre o modo de produzir as condições de existência em nosso país” (BRASIL, CNE, 2001, p.20). 
Os sentidos do retorno ao processo de escolarização para jovens e adultos assentados da reforma agrária da região de Promissão/São Paulo

Sobre o Território da Educação Rural, na Lei de Diretrizes e Bases da Educação Nacional - LDB (BRASIL, CNE, 1996) existem referências à educação rural, mas não trazendo grandes considerações sobre a diversidade presente neste ambiente, segundo o parecer. Afirma-se a necessidade da integração, inclusive no Art. 57 recomenda-se que os professores, que forem atuar em escolas do campo, busquem uma formação específica que considere a prática da aula relacionada ao meio. No Art. 105 é estipulado que a iniciativa pública pode apoiar instituições privadas que, em sua dinâmica educacional, efetivem a formação que leve o sujeito a se adaptar ao ambiente e ao mesmo tempo aguce suas vocações profissionais.

A pouca referência da educação do campo na LDB impulsionou a criação das Diretrizes Operacionais para a Educação Básica nas Escolas do Campo (BRASIL, CNE, 2001) para a especificidade desta vertente educativa. Desta forma, o Art.2 dessas diretrizes dá destaque para a necessidade de estabelecer a identidade da escola do campo, a partir da sua realidade, do conhecimento dos seus alunos, da memória coletiva, utilizando a ciência e tecnologia, atuantes na sociedade e vinculada a movimentos sociais que visam à oferta de melhor qualidade de vida coletiva.

Já no Art.6 reforça-se o compromisso do Poder Público em promover Educação Infantil e Ensino Fundamental nas comunidades rurais, mesmo para as pessoas que não concluíram em idade prevista seus estudos, cabendo ao Estado fornecer condições necessárias para que isso ocorra.

Nos assentamentos surgiu - segundo pesquisa realizada pelo Instituto Nacional de Colonização e Reforma Agrária - Incra, em 2010, que sinaliza que na Região Sudeste existiam 40.156 famílias assentadas - a necessidade de se criar uma política pública, como o Programa Nacional de Educação na Reforma Agrária - Pronera, que, por sua vez é desenvolvido pelo INCRA. Seu compromisso é com a alfabetização e a continuidade dos estudos, em todos os níveis de ensino para o indivíduo assentado. O programa

\section{(...) tem por objetivo ampliar os níveis de escolarização dos trabalhadores rurais assentados, atuando como instrumento de democratização do conhecimento no meio rural, ao propor e apoiar projetos de educação que utilizam metodologias voltadas para o desenvolvimento das áreas de reforma agrária" (VIEIRA, 2007, p.01).}

Na Pesquisa Nacional de Educação na Reforma Agrária realizada em 2004, mencionada no Manual de Operações do Pronera (2012), identificou-se que 23\% da população assentada era analfabeta. Além disso, trata-se de habitantes com níveis baixíssimos de escolaridade, além da pouca oferta de níveis escolares elevados nesses 
ambientes. Para reverter essa situação o Pronera definiu como seus princípios a inclusão, a participação, a interação, a multiplicação e a parceria. Sendo este último que permite a ação da Universidade Metodista de Piracicaba - Unimep, instituição da qual fazemos parte, que para tanto também se aliou ao movimento social da Organização das Mulheres Assentadas e Quilombolas do Estado de São Paulo - Omaquesp.

A realização da educação de jovens e adultos promovida dessa parceria deu origem a dois projetos, como os de 2005 a 2007 (Alfabetização) e de 2008 a 2010 (EJA). A terceira iniciativa envolve as regiões de Andradina, Itapeva e Promissão, onde se estima a participação de cerca de 600 assentados.

Ações como essas permitem que a discussão sobre educação se amplie, atingindo a reflexão sobre o acesso de direitos, "pois a população excluída do direito à educação é a mesma excluída do acesso a todos os outros direitos fundamentais" (VIEIRA, 2009, p.06). Além disso, nos permite aprimorar a formação dos educadores, pois estes passarão a ter acesso ao reconhecimento das expectativas dos educandos, a compreendê-las melhor, o que pode facilitar o diálogo que se busca enfatizar nas práticas educativas da EJA no Pronera.

\section{Metodologia}

Para a realização das entrevistas entramos em contato com uma das educadoras de jovens e adultos que atuam no Assentamento Reunidas. A opção por realizar a pesquisa na sala desta educadora deve-se ao fato desta ser a única educadora que também é assentada, além da questão de sua formação ter sido justamente em Pedagogia da Terra, que é ligada à realidade do campo. Pois, em nosso trabalho com os educadores do Pronera, todos os educadores são assentados da reforma agrária.

O nosso contato com os alunos ocorreu durante quatro dias, em que a maioria dos alunos participou das entrevistas, um total de 18 dos 22 alunos matriculados. Tratavamse dos alunos de umas das oito salas de aulas da EJA no município de Promissão, cinco delas no Assentamento Reunidas.

No primeiro dia, a bolsista do projeto de pesquisa participou de uma confraternização para os aniversariantes do mês e neste momento conversou com os alunos a respeito da pesquisa. Deste modo, nos dias seguintes, as entrevistas foram feitas tanto nas casas dos alunos quanto na sala de aula, o que permitiu tomarmos conhecimento 
Os sentidos do retorno ao processo de escolarização para jovens e adultos assentados da reforma agrária da região de Promissão/São Paulo

do cotidiano dos mesmos. Essa aproximação facilitou o desenvolver das entrevistas e permitiu um enorme engajamento de todos os envolvidos com o projeto.

\section{Conhecendo os Sentidos}

Quando nos propomos a investigar os sentidos do retorno ao processo de escolarização desses alunos, mergulhamos em um ambiente que pode ser concebido de modo múltiplo. A palavra "sentido" pode ser compreendida enquanto a faculdade de saber, então buscamos conhecer a forma como os alunos percebem esse retorno; já na compreensão enquanto acepção trata-se do significado que retornar aos estudos tem. Assim, quando perguntamos aos 18 alunos o que significa voltar aos estudos ou até mesmo ter a primeira experiência escolar, o que ouvimos foram mais do que respostas, eram histórias de vidas marcadas pela exclusão, mas também pelo desejo constante de aprender.

Na sala de aula, em que realizamos a pesquisa, localizada na Agrovila de Birigui, os alunos nos receberam com extremo entusiasmo, abraçaram a ideia e desejaram participar de nossas entrevistas.

Assim, antes de apresentarmos as entrevistas, consideramos relevante mencionar a história do espaço da escola, pois se trata de um espaço repleto de sentido e significado para os educandos e a própria história da escola tem relações diretas com o retorno dos educandos assentados ao processo de escolarização. Apresentamos, a seguir, esta história, conforme nos foi contada pelos educandos.

Essa sala de aula tem duas especificidades que enriquece a nossa discussão acerca do tema de nossa investigação. Trata-se, conforme explicitamos anteriormente, da única sala em que a educadora também é assentada. Esta educadora conhece desde a infância a luta pela conquista da terra, luta que foi vivida ao lado das famílias dos que hoje são seus alunos na sala da EJA. São famílias que vieram de diversas regiões do país, apostando num sonho, que implica a luta pelo direito de acesso à terra, em que pudessem cultivar e viver de sua produção.

De acordo com os educandos, eles se uniram em nome da reforma agrária, lutaram lado a lado, conquistaram a terra e passaram a viver como assentados. Mas, com o passar dos anos, com a rotina pesada da roça e o cuidado com a família, viram-se isolados em seus lotes e, de algum modo, estas famílias tinham um questionamento comum: Como estaria aquele amigo antigo? Será que vai bem o compadre? 
O desejo de estudar, seja pela primeira vez ou retomando um tempo que ficou muito lá atrás, possibilitou uma nova união destas famílias, desta vez em busca de recuperar o espaço da escola, para que pudessem retomar os estudos. Esta luta permitiu que os antigos laços de amizade e lutas fossem resgatados e aí estaria a segunda especificidade. Há anos, quando seus filhos ainda eram crianças, os assentados lutaram para a construção de uma escola na própria Agrovila de Birigui, para que esses não precisassem ir para o centro de Promissão - "pra cidade" - para poderem estudar. A escola foi então construída a partir de uma demanda do próprio assentamento. Retratava o orgulho da conquista da escola para os filhos.

A escola sempre foi espaço de luta e a prefeitura sempre argumentava que não compensava enviar professores para ela. No entanto, com o passar do tempo, gradativamente todos os alunos foram transferidos para o centro da cidade e, durante oitos anos a escola ficou fechada e foi se deteriorando pela ação do tempo, sendo que vez ou outra apenas uma das três salas era usada por médicos, que compareciam periodicamente para prestar atendimento à população do assentamento.

Foi então que surgiu a oportunidade de dar vida novamente para aquele espaço. A Agrovila Central havia aberto uma sala da EJA, mas esta não atendia às necessidades dos assentados da Agrovila de Birigui. Para ir a esta escola o assentado tinha que se deslocar por longa distância e a noite, após o dia de trabalho braçal, este deslocamento era inviável. Assim, surgiu o questionamento: Por que não abrirmos uma sala ali mesmo na escola fechada? Seria preciso saber quem realmente estava interessado e assim começou-se a busca feita pelos próprios assentados, a fim de convencer a prefeitura a abrir uma sala de aula da EJA na Agrovila de Birigui também.

(...) ficamos felizes com o prédio reformado e onde os meus filhos estudaram
ai depois nós estudamos. Estamos felizes porque voltamos a estudar.
Chegamos lá e vemos: nossa onde os meus filhos estudaram eu estou
estudando, aprendendo ler, parabéns para mim! (risos) - Aluna L

A escola dos filhos era agora a escola deles. Não eram mais os pais ou avós dos alunos, eram eles os próprios alunos. De lote em lote, com uma prancheta nas mãos foram colhendo os nomes dos interessados e, assim, tinham uma lista de 22 pessoas que em agosto de 2013 começaram os seus estudos. Com o passar dos meses alguns precisaram se ausentar por motivos de saúde, mas a turma manteve-se forte e principalmente unida. Estudar, que sempre foi um objeto de desejo e negado muitas vezes pela necessidade de ter que trabalhar desde muito novo, parecia agora, mais do que nunca, possível. O sonho seria então realizado, e ainda de forma surpreendente. 
Os sentidos do retorno ao processo de escolarização para jovens e adultos assentados da reforma agrária da região de Promissão/São Paulo

Para estudar ali (sítio muito afastado) não tinha condições, e da idade de sete para oito anos já fui trabalhar para ajudar meu pai criar os mais pequenos (irmãos mais novos). Porque naquele tempo a lei era essa. Não tinha condições, não tinha escola por perto e estudava assim: aqueles filhos que tinham condições. - Aluno Z, parênteses nossos

Vimos na maioria das falas que o motivo de deixar a escola ou mesmo nunca ter estado em uma se deu pela necessidade de trabalhar, seja no caso do cuidado com irmãos mais novos ou mesmo caminhando junto com os pais. Um trabalho de roça, em vários casos, que lhes roubou a infância, na qual, desde cedo, a responsabilidade os forçou a abrir mão de muitos direitos, dentre eles o direito à educação.

Parece assim, teve um tempo que teve escravo, mas nós éramos escravos também. (...) Com japonês você não parava nem dia de domingo, por isso que eu falo que éramos escravos (...) O sol já tinha escondido daí era hora de irmos embora. Então os negros foram escravos, mas eu também fui escravo. - Aluno $\mathbf{Z}$

Quando acessamos os cadernos do MEC ligados a EJA (2006a, 2006b) vimos o quão forte era a afirmação de como muitos jovens e adultos abrem mão dos seus estudos, pela necessidade de ter que trabalhar. Mas, neste mesmo material, a discussão seguinte mostra que os motivos que os tiram da escola é o mesmo que os fazem retornar a esta.

Em nossas entrevistas, o retorno à escola se dá por algo muito maior do que conquistar um novo emprego ou um emprego melhor. Percebeu-se claramente que a escola é para eles sinônimo de conquista e as aulas, momento de abordar questões da vida cotidiana que se mostram desafiadoras no âmbito individual, mas, ao serem compartilhadas, percebe-se comumente que são coletivas e que há possibilidades de busca conjunta por superação destas questões.

O ir à escola não é uma busca ansiada por certificação, uma mera escolarização, muito pelo contrário, a ânsia existe, mas em aprender e, se for necessário, passar do horário da aula para poder saber mais. Aqui vemos a distinção entre a escolarização, que visa ao conhecimento apenas utilitário que ambiciona o certificado, e o processo educativo, que almeja a obtenção de conhecimento, a fim de potencializar a vida. $\mathrm{O}$ valor de poder escrever o seu pensamento. As palavras passam a ser armazenadas não para montar uma coleção em suas memórias e sim para que tenham novos instrumentos para “escrever o seu mundo, o seu pensamento, para contar sua história” (FREIRE, 1987, p.07).

Os alunos trazem de forma muito forte em seus relatos e um tanto quanto singular a sua compreensão de educação como capacidade de saber "entrar e sair dos lugares", entender as pessoas e ser entendido pelos outros ao seu redor. Poderíamos compreender 
que aprender a ler e escrever não se restringe a possuir técnicas e sim a aumentar as opções de aprender para poder ver e ser visto.

Nossa é a coisa mais triste que tem. Somos que nem um cego. É cego sobre a leitura. Vai em um lugar e tem que ficar perguntando, não sabe né... Mas agora eu estou tentando, lutando e lutando. - Aluna L

Aprender, ter educação, saber entrar, saber sair, saber conversar, saber explicar, saber... tudo isso. É bom! - Aluna B

Uma educação que promove movimento, transformação e a possibilidade de maior autonomia, a oportunidade de ser autor e autora de sua própria história, de a "escrever" de outras formas. Talvez com menos sofrimentos e mais conquistas, só que, mais do que isso, sendo mais autor daquilo que sempre deveria ser seu, proprietário não apenas da sua sonhada terra, mas agora também da sua história. "Talvez seja este o sentido mais exato da alfabetização: aprender a escrever a sua vida, como autor e como testemunha de sua história, isto é, biografar-se, existenciar-se, historicizar-se.” (FREIRE, 1987, p.05).

Quando entramos em contato com a compreensão de Ciampa (2005) referente à constituição da identidade, como um processo de morte-e-vida de personagens no decorrer de nossas vidas, um ponto se assemelha ao que Freire (1987) acredita ser o papel da alfabetização. O que faz com que o personagem do qual somos seja, no momento atual, nos mais diferentes grupos que estamos relacionados, mais autônomo é quão autores de nossa própria histórica somos. Por exemplo, uma pessoa que esteja estudando é então considerada um aluno, mas sua autonomia se dará a partir do momento em que ela se sinta autora do seu processo de aprendizagem, alguém que escreve o roteiro da própria vida e não apenas interpreta um texto pronto, dado por outro alguém. Autonomia é, tanto para Ciampa quanto para Freire, e que podemos enxergar na experiência de vida dos alunos assentados, estar em posição de destaque em sua própria vida. Não seria viver conforme um ator, que segue o enredo escrito por outra pessoa, pessoa que representaria uma sociedade que infelizmente ainda exclui milhares de sujeitos de seus direitos primordiais.

Quando os alunos que ouvimos foram por conta própria atrás de reabrir a escola foi necessário, primeiramente, reconhecer que um direito que lhe fora negado durante a vida toda que poderia ser resgatado, mas que isso só se daria pela união do coletivo. Freire (1987) acreditava que o processo de ser mais do ser humano, a humanização, era negado pela opressão, causando desumanização tanto para quem a realiza como por quem que a recebe. Assim, opressor e oprimido não vivem o ser mais e se desumanizam. 
Os sentidos do retorno ao processo de escolarização para jovens e adultos assentados da reforma agrária da região de Promissão/São Paulo

A solução, para ambos, viria, portanto, da união dos oprimidos, já que o opressor não abriria mão do poder conquistado, mesmo resultando na sua própria desumanização. Quando esses alunos se unem para obter o sonho de saber ler e escrever não é apenas a alfabetização que se efetiva, mas também a oportunidade de, em coletivo, ver que a união pode permitir que seus direitos sejam restaurados. Não apenas o direito a educação, mas os mais diversos que possam estar relacionados: saúde, transporte, lazer etc.

Ir para a escola não é algo cansativo, enfadonho e sim se mostra como a possibilidade de aprender, coisas novas e também as mesmas coisas, mas de novas formas. Até mesmo o cotidiano da roça pode ser visto com outros olhos, os horizontes podem ser modificados, mesmo que os olhos estejam orientados para a mesma a direção. A teoria aprendida na sala de aula promove reflexões a respeito da prática, de forma que ambas se alteram e, assim, se agregam e valorizam. Quando a vida fora da sala de aula começa a se modificar, quando é visível, a crença na própria capacidade é, então, construída. $\mathrm{O}$ aluno pode se perceber como um sujeito de potência, um ser capaz.

Hoje se eu for comprar, vamos supor, defensivo agrícola para a roça. Então eu pego e já faço as contas: vai ter tanto, vai ser tanto. Eu já sei. Eu fazia na cabeça, mas eu fazendo na cabeça já já esquecia ela. (...) Eu estou sentindo que eu já estou aprendendo bastante. - Aluno $\mathbf{Z}$

Aprendi mais a conversar, a educar as palavras, mas eu ainda tenho muita dificuldade em conversar. Mas eu estou me saindo bem. (...) Ah mudou bastante nossa! A convivência minha com o meu marido, que ele era muito fechado comigo, quase não conversava, agora a gente senta e conversa, conta causo, sabe? Isso mudou muito para mim também, ajudou bastante. Nós sentamos, fazemos lição. O que ele não sabe eu ensino, o que eu não sei ele me ajuda. - Aluna I

O resgate não é apenas do processo de alfabetização, mas do reconhecimento do seu potencial. Esses alunos, ao voltarem aos estudos, puderam resgatar a elaboração do orgulho de sua própria história, uma história de luta e conquista, e o analfabetismo que parecia ser motivo de vergonha cedeu espaço para acreditar que é possível aprender sempre e recuperar o que por muito tempo não tiveram acesso. A felicidade estampada nos rostos de cada aluno representa os passos dados nos oito meses que já tinham trilhado, quando tivemos contatos com suas narrativas, eram motivos que os faziam acreditar ser possível ir além. Ir além não quer dizer arrumar um emprego "na cidade" e deixar de trabalhar na roça, mas justamente potencializar o seu cotidiano, valorizando aquilo que anteriormente conquistou a partir da luta e da união. Conquistar gradativamente cada vez mais autonomia em cada personagem de sua vida: como pai, mãe, filho, assentado, aluno, amigo, esposo, esposa. 


\subsection{A Sala de Aula como um ambiente que potencializa a vida comunitária}

O dia-a-dia na sala de aula não se constitui apenas em momentos dos quais se acolhe conhecimentos sistematizados, mas que também promovem discussões que caminhem para reflexões. Reconhecer-se como fruto da história e por isso fazer parte de um coletivo, não sendo nunca um ser isolado.

Infelizmente, alguns processos educativos empregados pela maioria das escolas colocam o aluno como aquele a que lhe é negada a possibilidade de fazer história. Um receptáculo que só deve acumular informações, mas não as digerir para tirar novas conclusões que construam novos saberes. Mas o ambiente oferecido a esses alunos assentados, na sequência da conquista da reabertura da escola, reafirma o valor da união. Eles se reconhecem novamente como uma comunidade, um convívio que permite apoio, acolhida e compartilhamento, que mostra que mesmo com a idade avançada de alguns ainda é possível conhecer sobre o mundo. Além disso, é possível conhecer junto com o outro.

Se a gente realmente ficasse dentro da casa da gente nós não íamos aprender nada. Nós temos que ir na aula mesmo. Estudar, trocar ideias, ter umas ideias diferentes, é muito bom trocar ideia. A gente passa o que a gente sabe, as pessoas passam o que sabem para a gente. - Aluna $\mathbf{T}$

(...) aqui nós não sai muito e não tem quase o que fazer, então a gente tem um problema, às vezes eu passei um nervoso ou alguma coisa, eu chego lá (na escola) e baixa a minha pressão. (...) A gente se dá mais do que uns irmãos na carne, porque a gente sente falta um do outro. - Aluna $\mathbf{L}$ *parênteses nosso

Eu acho assim bom, porque fica que nem uma comunidade reunida nessa sala. A gente discute, conversa e parece que os amigos se juntam mais. Daí vira aquela comunidade bonita que nem você viu aquele dia - Aluna M

Mesmo dando ainda seus primeiros passos, a construção de um espaço tão agradável de estar tem um motivo: o valor do diálogo. A educadora desta turma não é apenas uma professora, é assentada, considerada amiga e reconhecida por muitos como uma filha. Uma pessoa que, dentre poucas das que passaram na vida de cada uma desses alunos, respeitou o conhecimento dos mesmos.

Uma representante da concepção de Paulo Freire que acredita no saber do aluno e vê este saber como o fundamental das ferramentas para o processo de aprendizagem. Para Freire (1987), quando a discussão é formada pelos diálogos, não são mais as palavras que estão sendo copiadas, são os próprios juízos que estão ganhando expressão. Um processo de produção e elaboração, que permite ver a condição de modificar o mundo à sua volta e não apenas ser modificado por ele. 
Os sentidos do retorno ao processo de escolarização para jovens e adultos assentados da reforma agrária da região de Promissão/São Paulo

Para mim está muito bem, é muito bom, ótima professora. A gente ama muito ela, nós até pensamos de um dia ela não vir mais para cá. (...) Ela é muito bacana, ela é muito família, nossa ela não é professora ela é a nossa irmã, uma tia, uma amiga, uma mãe. - Aluna I

Isso só pode se efetivar a partir do momento em que os saberes construídos na vivência fora da escola, que foram elaborados por esses alunos durante suas vidas, são ponto de partida ao que se pretende apresentar dentro da sala de aula. Uma educação que tem como essência a valorização do conhecimento e da cultura do grupo e que contextualiza o ensino, a partir das experiências deste grupo, que uma vez reconheceu no coletivo aquilo que primeiramente parecia ser particular. Uma educação que, segundo Freire, apresenta-se como prática da liberdade.

E se já pensávamos em método ativo que fosse capaz de criticizar o homem através do debate de situações desafiadoras, postas diante do grupo, estas situações teriam de ser existenciais para os grupos. Fora disso, estaríamos repetindo os erros de uma educação alienada, por isso instrumental. (FREIRE, 1967, p.106)

Os olhos que brilham não eram apenas dos alunos, mas também de sua educadora com a qual tivemos contato. $\mathrm{O}$ empenho em realizar aulas motivadoras, que fujam o máximo possível de memorizações e repetições, que respeite o tempo de cada um, é recompensado com o vínculo criado a favor da educação, que é exercido com enorme empenho por parte dos alunos. Alunos que desejam aprender, saber mais, que têm sede por recuperar aquilo que, por muito tempo, lhes foi negado. Alunos que se sentem felizes por se observarem inseridos novamente em uma comunidade, em um grupo que os valoriza e os apoia e que não se restringe a pensar em si apenas, mas que, enquanto grupo, pensa o coletivo.

\section{Considerações Finais}

A Educação de Jovens e Adultos - EJA é compreendida por esses alunos como a retomada de uma oportunidade que lhes foi negada por anos, pelos mais diversos motivos, envolvendo muitas vezes a questão do trabalho pesado da roça. Momentos que proporcionam por vezes a sensação de voltar a ser criança, porém não no sentido de reduzir-se, mas como se o frescor por aprender presente na infância estivesse de novo presente em suas vidas.

As dificuldades, como o cotidiano árduo de trabalho que às vezes deixa os olhos mais pesados de sono não impede que os mesmos olhos tenham ânsia pelo saber. A idade 
avançada e as longas distâncias percorridas não são empecilhos e sim o reconhecimento de que muito já aprenderam nessa vida, mas que sempre é possível aprender mais.

A vivência desses alunos nos coloca aquilo que Ciampa (2002) discute a respeito de política de identidade e identidade política. A identidade política é "a participação social na disputa por significar o real" (CIAMPA, 2002, p.141). Um processo em que se olha para o específico sem perder a visão do geral. Seria um misto de personagens, em que uma, mais do que as outras estariam ativamente engajadas em ações coletivas, sem perder sua natureza pessoal e singular, como no caso das personagens Aluno e Assentado. Quando esses sujeitos colocam-se frente às barreiras impostas pelas ideologias a respeito do Sem-terra e o Analfabeto, que são preconceitos que constroem as políticas de identidade que marginalizam essas pessoas, eles estão politizando as suas identidades, isto é, construindo identidades políticas.

Esses mesmos homens e mulheres, que anteriormente se uniram para lutar contra o estigma de não ter terra própria para construir o seu sustento, negam a política de identidade que menospreza o seu ideal de luta. Agora, a união é retomada para lutar contra o preconceito que sofrem por serem analfabetos, para eliminar o estigma que impede autonomia em níveis mais avançados, por ser considerado o "sujeito-que-não-sabe-ler-eescrever".

\section{REFERÊNCIAS BIBLIOGRÁFICAS}

BArreto, V. (Org.); COSTA, E.; ÁlVARES, S. Cl. Alunos e Alunos do EJA. Caderno 1. Coleção Trabalhando com a Educação de Jovens e Adultos (2006a). Disponível em: 〈http://portal.mec.gov.br/ arquivos/pdf/ejacaderno.pdf>. Acesso em: 24 set. 2013.

O Processo de Aprendizagem dos Alunos e

Professores. Caderno 5 Coleção Trabalhando com a Educação de Jovens e Adultos (2006b). Disponível em:

<http://portal.mec.gov.br/secad/arquivos/pdf/eja_caderno5.pdf>. Acesso em: 25 nov. 2013.

BARRETO, Vera. Paulo Freire para Educadores, São Paulo/SP: Editora Arte e Ciência, 1998.

BRASIL. CONSELHO NACIONAL DE EDUCAÇÃO - CNE. Diretrizes Curriculares Nacionais para a Educação de Jovens e Adultos. Brasília - DF: MEC, 2000 . 
Os sentidos do retorno ao processo de escolarização para jovens e adultos assentados da reforma agrária da região de Promissão/São Paulo

BRASIL. CONSELHO NACIONAL DE EDUCAÇÃO - CNE. Diretrizes Operacionais para a Educação Básica nas Escolas do Campo. Brasília - DF: MEC, 2001.

BRASIL. MEC/Inep. O Mapa do Analfabetismo no Brasil (2003) Disponível em: <www.oei.es/quipu/brasil/estadisticas/analfabetismo2003.pdf >. Acesso em: 03 jan. 2014.

CALDART, Roseli Salete. Movimento Sem Terra: Lições de Pedagogia. Revista Currículo sem Fronteiras, v.3, n.1, p. 50-59, jan./jun. 2003. Disponível em: $<$ http://www.curriculosemfronteiras.org/vol3iss1articles/roseli1.pdf>. Acesso em: 29 abr. 2016.

CIAMPA, Antonio da Costa. A estória do Severino e a história da Severina. São Paulo - SP. Ed. Brasiliense, 2005.

Política de Identidade e Identidades Políticas.

Texto elaborado a partir de apresentação de mesa redonda no I Congresso Brasileiro Psicologia: Ciência e Profissão, realizada em 03/09/2002.

D’AQUINO, Teresinha. Assentamento Como Nova Forma de Vida Rural: Espaço e Tempo no Assentamento Rural da Fazenda Reunidas - SP. Raízes: Revista de Ciências Sociais e Econômicas, Campina Grande, v. XVI, n. 15, p.47-61, dez. 1997. Disponível em: 〈http://www.ufcg.edu.br/ raizes/artigos/Artigo_157.pdf>. Acesso em: 28 abr. 2016.

FREIRE, Paulo. Educação como Prática da Liberdade. Rio de Janeiro: Editora Paz e Terra. 1967.

Paz e Terra, 1999.

Pedagogia da Autonomia. São Paulo - SP: Ed.

Editora Paz e Terra, 1987.

Pedagogia do Oprimido $17^{\mathrm{a}} \mathrm{Ed}$. Rio de Janeiro:

(Questões de Nossa Época, v. 23).

Política e Educação. São Paulo: Cortez, 2001

Instituto Nacional de Colonização e Reforma Agrária - Incra. Manual de Operações do PRONERA 2012. Portaria/Incra/P/N 238, de 31 de maio de 2011 Disponível em: <http://www.incra.gov.br/index.php/servicos/publicacoes/ manuais-eprocedimentos/file/654-Pronera>. Acesso em: 04/01/2014.

IOKOI, Z. M. G.; ANDRADE, M. R. de O.; REZENDE, S.; RIBEIRO, S. Vozes da terra: histórias de vida dos assentados rurais de São Paulo. Assentamento Reunidas. p. 174 - 205. — São Paulo: Fundação Itesp, 2005. Disponível em:

<http://diversitas.fflch.usp.br/files/05-Assentamento\%20Reunidas.pdf>. Acesso em: 28 abr. 2016. 
SOARES, Magda. Letramento: um tema em três gêneros. Belo Horizonte, Editora Autêntica, 2001.

VIEIRA, Márcia Aparecida Lima. Educação em assentamentos rurais: avaliando a experiência de Alfabetização no PRONERA - Programa Nacional de Educação na Reforma Agrária. Piracicaba, 2007. Disponível em:

<http://www.unimep.br/phpg/mostraacademica/anais/5mostra/2/29.pdf > . Acesso em: 09 set. 2014.

PRONERA: Vivências e Desafios da Educação

de Jovens e Adultos nos Assentamentos. Campinas, 2009. Disponível em:

<http://alb.com.br/arquivo-

morto/edicoes_anteriores/anais17/txtcompletos/sem02/COLE_2513.pdf >. Acesso em: 09 jan. 2014.

Recebido em: 21/02/2016

Aprovado em: 22/05/2016 